\title{
A FORMAÇÃO DO IUS COMMUNE E O HUMANISMO
}

\author{
THE FORMATION OF THE IUS COMMUNE AND HUMANISM
}

\section{Maria Cristina da Silva Carmignani*}

\begin{abstract}
Resumo:
$\mathrm{O}$ artigo tem por objeto a ciência jurídica medieval, desenvolvida dentro das universidades durante a baixa idade média, que resultou na formação do ius commune, bem como as transformações produzidas a partir do séc. XVI pela jurisprudência humanista.

Palavras-chave: Universidades. Baixa idade média. Ius commune. Humanismo.

Abstract:

The main goal of this paper is to present the legal medieval science, developed in universities along the Late Middle Ages, that resulted in the formation of the ius commune, as well as the changes produced by the humanist jurisprudence.
\end{abstract}

Keywords: University. Late Middle Ages. Ius commune. Humanism.

\section{A Formação do ius commune}

Segundo António Manuel Hespanha, o termo que melhor designa a doutrina jurídica dos séculos XV, XVI e XVII é a de "direito comum", ainda que tenha recebido variadas designações: bartolismo, escolástica jurídica, mos italicus, etc. (HESPANHA, 1998, p. 66).

Ainda, usando as palavras do citado autor, a utilização da referida designação dá a ideia do que representa essa doutrina, tendo como característica principal a unidade: (HESPANHA, 1998, p. 66).

(i) Quer enquanto unifica as várias fontes do direito (direito justinianeu, direito canônico e direito local);

(ii) Quer enquanto constitui um objeto único (ou comum) de todo o discurso jurídico europeu;

(iii) Quer ainda enquanto "trata" este objeto segundo métodos e estilos de raciocinar comuns;

(iv) Forjados em um ensino universitário do direito que era idêntico por toda a Europa e;

\footnotetext{
* Professora Doutora do Departamento de Direito Civil (área História do Direito) da Faculdade de Direito da Universidade de São Paulo. 
(v) Vulgarizados por uma literatura escrita em uma língua então universal - o latim.

Diversos fatores contribuíram para a formação dessa unidade jurídica, em especial a formação intelectual dos juristas, que era homogênea.

Essa homogeneidade resultava, por seu turno, da utilização da mesma língua - o latim - da mesma formação metodológica, adquirida nos estudos preparatórios universitários, ${ }^{1}$ como a lógica e a retórica e, principalmente, pelo fato de todo o ensino jurídico se pautar no direito romano e canônico.

Além disso, no plano político, a reconstituição do Império - Sacro Império Romano - Germânico (séc. X) - inspirado no Império Romano, assim como a unidade religiosa - a Igreja ecumênica - levavam a ideia de certa unidade do direito (HESPANHA, 1998, p. 66).

Mesmo naquelas localidades onde a autoridade do direito romano não pudesse provir de autoridade do imperador, impunha-se em virtude da superior perfeição atribuída a esse direito. Tal fato se dava em razão da superioridade das fontes romanas face aos direitos germânicos alto-medievais ou aos direitos locais.

As soluções romanas, explicitadas pelos juristas, abarcavam a maior parte das questões da época, e sua ratio, bem como a aequitas e a utilitas passaram a orientar o saber jurídico europeu.

Esse saber jurídico universitário, fundado no direito romano, foi disseminado pelos círculos mais elevados do poder imperial, influenciando inclusive na própria legislação local, influência dos letrados presentes nas chancelarias reais.

Uma teoria jurídica universal significava, no dizer de Franz Wieacker,

(...) também na oportunidade de manter um monopólio técnico da capacidade para arbitrar as questões (...) o que se tornava particularmente importante perante a inabarcável dispersão do direito e o constante conflito de várias ordens jurídicas locais (...). (WIEACKER, 1967, p. 80).

A construção dessa teoria jurídica universal foi fruto do trabalho dos comentadores, "que prosseguiram com o trabalho de interpretação teórica dos glosadores sobre o Corpus Iuris em ligação com a tarefa de ensino, também por eles mantidas" (WIEACKER, 1967, p. 81).

Os comentadores procederam a uma renovação do objeto de seus estudos e dos seus problemas, aproximando o direito romano (ou melhor, direito justinianeu), dos

A base do ensino medieval se dava com o estudo das artes liberais, dividido em trivium (dialética, retórica e gramática) e quadrivium (aritmética, geometria, astronomia (astrologia) e harmonia (música)). 
direitos estatutários (direito local), considerando estes últimos como um direito especial, com uma interpretação, portanto, mais restrita.

A práxis italiana moveu-se no sentido de aceitar a multiplicidade de fontes: mas, na prática, houve uma sobrevalorização da teoria unificada do "ius commune" (WIEACKER, 1967, p. 81).

Aos poucos, no entanto, os comentadores passaram a submeter todas as fontes à sua técnica científica - sem perder a unidade do direito comum - “... forçar o sentido textual mais do que interpretá-lo, só com os consiliadores, muitas vezes com recurso a ousados expedientes dialécticos" - passaram a criar novas figuras jurídicas, transformando-se em precursores da moderna dogmática do direito privado. (WIEACKER, 1967, p. 83).

A série dos nomes mais célebres de comentadores, conhecidos até o século XVII começa com:

- Cino de Pistóia (1270 - 1336);

- Bártolo de Saxoferrato (1314 - 1357) - o mais célebre dos juristas, trabalhou em Perúgia;

- Baldo de Ubaldis (1327 - 1400) - mais novo, mais sintético, mais rico e preciso do ponto de vista intelectual;

- Paulus de Castro e Jason de Mayno (século XV) - contemporâneos da recepção prática ao norte dos Alpes).

O compromisso prático dos comentadores ligados à sua extraordinária reputação, como detentores do monopólio intelectual e do prestígio do direito romano, levou a publicação dos seus pareceres em uma literatura conciliar que dominou a cultura jurídica do direito comum, até as vésperas das codificações jus naturalistas, além de comentários e monografias que justificavam as instituições contemporâneas com adequados textos do Corpus Iuris, do direito local e estatutos, incorporando-os ao direito comum.

O studium civile em Bolonha constituiu um primeiro renascimento, uma renovação criadora da jurisprudência da antiguidade, renovação essa ligada na crença nas autoridades e método escolástico de ensino (WIEACKER, 1967, p. 89, nota 39).

A probabilidade como base do conhecimento científico medieval, apoiado na opinião dos doutores.

A communis opinio doctorum resultou, assim, da opinião dos juristas, inicialmente resultante da opinião de uma autoridade individual, segundo um critério qualitativo, pautado na razoabilidade dos argumentos, ao que, depois, a partir do século $\mathrm{XV}$, passa a decorrer da opinião de autoridades coletivas, que reunisse o maior número de intérpretes, ou seja, de acordo com um critério quantitativo. 
2. O humanismo e a transformação da jurisprudência

A partir do século XIV, em decorrência do Renascimento cultural, artístico e científico que ocorreu na Itália, despontou o humanismo, um movimento intelectual que se voltou à Antiguidade Clássica e levou a revalorização da ciência, da arte e da filosofia clássica, adaptadas ao novo contexto histórico.

No campo do direito, o humanismo veio se opor às autoridades medievais e as formas de conhecimento da escolástica, que dominava, como se disse, a ciência jurídica medieval.

Segundo descreve Claúdio de Cicco,

A visão teocêntrica do universo cedeu lugar a uma concepção nova, o Antropocentrismo ou Humanismo, em que o homem ocupa o centro de todas as coisas. Essa nova concepção do universo, ou cosmovisão, conduziu a um novo teor de vida e, consequentemente, a novas instituições, que substituíram, por vezes violentamente, as antigas. (CICCO, 2006, p. 101).

O impulso do humanismo é "a ideia de uma volta à antiguidade com a experiência originária de uma nova ideia do homem e do mundo". (WIEACKER, 1967, p. 90).

A meditação filosófica de Giovanni Pico della Mirandola mostra-se como um reflexo exemplar do humanismo renascentista, envolvendo o conceito de humanismo como valorização e promoção dos valores do homem, por intermédio do seu intelecto (racionalidade) que, por meio deste, poderia compreender o seu ser, a sua essência, que era a sua dignidade. ${ }^{2}$

Desta forma, no campo jurídico o humanismo provocou o regresso da jurisprudência às fontes autênticas, sem a mediação das autoridades medievais.

A jurisprudência humanista pretendia transformar o direito: "pretendia simplificar o direito, torná-lo acessível a qualquer homem do bem, e arrancá-lo dos pedantes da Faculdade, dos técnicos do bartolismo, dos juristas especializados”. (VILLEY, 2009, p. 543).

Nas palavras de Franz Wieacker os humanistas pregavam "As fontes puras em vez da tradição, o conhecimento das ideias em vez da comprovação das autoridades por meios lógicos, o sistema em vez da exegese". (WIEACKER, 1967, p. 92).

2 Ver a respeito do renascimento, a obra de Giovanni Pico della Mirandola, Conde de Concordia e de Mirandola, o mais famoso e conhecido texto que representa o primeiro momento do renascimento - PICO DELLA MIRANDOLA, Giovanni Francesco. Discurso sobre a dignidade do homem. Tradução Maria de Lurdes Sirgado Ganho. 6. ed. Lisboa: Edições 70, Lda, 2010. Edição Bilíngue. 
Os humanistas apontavam graves falhas nas interpretações feitas pelos glosadores e comentadores, pela ignorância filológica e antiquarista dos juristas técnicos, bem como pela utilização de um latim vulgar.

Os juristas humanistas vão dar uma nova valoração ao direito romano, considerando o seu sentido histórico, discutindo a sua vigência e a interpretação dada pelos juristas medievais, recebendo a denominação de juristas cultos, ou elegantes.

Como muito bem colocado por Nuno Espinosa, são "comentadores animados de um espírito de liberdade que os leva a procurar a verdade do texto, e não a communis opinio". (SILVA, 1991, p. 331).

Em razão de que esse método inovador de interpretação do direito romano alcançou maior expressão na França, com Cujácio, acabou recebendo a denominação de mos gallicus, ${ }^{3}$ embora tenha tido o seu berço na Itália, com o mestre Alciato.

Assim, o mos gallicus, como vertente do humanismo, construiu um direito teórico, de tendência erudita, ao passo que o mos italicus levou a um direito prático, com a utilização do direito romano para solução de casos concretos. (COSTA, 1996, p. 319).

Essas duas escolas interpretativas do direito romano ocuparão o palco da ciência jurídica, especialmente no século XVI, como representativas dos métodos denominados de "mos italicus" e "mos gallicus".

O humanismo abalou em parte o prestígio e a tradição do mos italicus, ${ }^{4}$ mas não o venceu, preponderando essa forma de estudo e aplicação do direto ainda por muito tempo na Europa, exceto em parte da França e Holanda.

Como muito bem colocado por Mario Júlio de Almeida Costa, "o programa do 'mos gallicus' apresentava-se, de qualquer modo, não só mais difícil de executar, mercê da preparação científica que exigia, mas também menos atractivo para a rotina forense", de forma que prevaleceu "o sentido pragmático dos juristas de formação bartolista". (COSTA, 1996, p. 319).

São Paulo, agosto de 2017.

\section{Referências}

CICCO, Claudio de. Filosofia do direito. 3. ed. São Paulo: Saraiva, 2006.

COSTA, Mário Júlio de Almeida. História do direito português. 2. ed. Coimbra: Almedina, 1996.

\footnotetext{
3 A acolhida desse método inovador de estudo e interpretação do Direito Romano se justifica pelo fato de que no norte e no centro da França a recepção do ius commune não tinha sido muito intensa, tendo em vista a importância do direito costumeiro.

4 Maneira de estudar e interpretar o Direito Romano que se consolidou na Itália, pelos comentadores, com base no método escolástico, visando a sua aplicação prática.
} 
HESPANHA, António Manuel. Panorama histórico da cultura jurídica europeia. 2. ed. Portugal: Publicações Europa-América, 1998.

PICO DELLA MIRANDOLA, Giovanni Francesco. Discurso sobre a dignidade do homem. Tradução Maria de Lurdes Sirgado Ganho. 6. ed. Lisboa: Edições 70, Lda, 2010. Edição Bilíngue.

SILVA, Nuno J. Espinosa Gomes da. História do direito português: fontes de direito. 2. ed. Lisboa: Fundação Calouste Gulbenkian, 1991.

VILLEY, Michel. A formação do pensamento jurídico moderno. 2. ed. São Paulo: WMF Martins Fontes, 2009.

WIEACKER, Franz. História do direito privado moderno. 2. ed. Lisboa: Fundação Calouste Gulbenkian, 1967. 